\title{
On the Fate of Protests: Dynamics of Social Activation and Topic Selection Online and in the Streets
}

\author{
Ahmadreza Asgharpourmasouleh, Masoud Fattahzadeh, Daniel Mayerhoffer, \\ and Jan Lorenz
}

\begin{abstract}
This chapter studies individual and network conditions for the emergence of large social protests in an agent-based model. We use two recent examples from Iran and Germany to inform the modeling process. In our agent-based model, people, who are interconnected in networks, interact and exchange their concerns on a finite number of topics. They may start to protest either because of their concern or because the fraction of protesters in their social contacts exceeds their protest threshold. In contrast to many other models of social protest, we also study the coevolution of topics of concern in the not (yet) protesting public. Given that often a small number of citizens starts a protest, its fate depends not only on the dynamics of social activation but also on the buildup of concern with respect to competing topics. Nowadays, this buildup happens decentralized through social media. The model reproduces characteristic patterns of the evolution of the two empirical cases of social protests in Iran and Germany. In particular, our results show that positions of agents with certain concern levels on certain topics within the networks are important for the fate of protests.
\end{abstract}

Keywords Opinion dynamics $\cdot$ Social protest $\cdot$ Social media $\cdot$ Social network

\footnotetext{
A. Asgharpourmasouleh $(\bowtie) \cdot$ M. Fattahzadeh

Ferdowsi University of Mashhad, Mashhad, Iran

e-mail: asgharpour@um.ac.ir; masoud.fattahzade@mail.um.ac.ir

D. Mayerhoffer

Universität Bamberg, Bamberg, Germany

e-mail: Daniel.mayerhoffer@uni-bamberg.de

J. Lorenz

Jacobs University Bremen, Bremen, Germany

Universität Bremen, Bremen, Germany

GESIS Leibniz Institute for Social Sciences, Cologne, Germany

e-mail: post@janlo.de
}

(C) The Author(s) 2020

E. Deutschmann et al. (eds.), Computational Conflict Research,

Computational Social Sciences, https://doi.org/10.1007/978-3-030-29333-8_7 


\section{Introduction}

Street protests frequently happen all over the world. In the USA alone, from January 20, 2017 to June 16, 2019, 13,761 protests with 10,827,646 attendees have been recorded (Count Love 2019). Street protests are typical examples of emergent social phenomena that result from the interaction of many heterogeneous and autonomous agents. Changes in the number of attendees and topics of protest are inherent in street protests as the case of Russia from 2007 to 2013 shows (Lankina 2014). By topic of protest, we mean the main issue that protesters address in a protest. After the emergence of a protest, slogans and behavior of protesters, peaceful or violent, influence how others judge it and may constrain more people from joining.

New technologies, specifically social media, have changed our communication. They made cheap and fast interactions among a large number of actors in a decentralized ways possible (assuming that administrators of social media do not intervene in interactions). These technologies have helped to organize protests. A protest announcement can reach millions in no time without central control. Moreover, they have enabled amateur multimedia reporters to broadcast details of the protest in real time.

On the other hand, social media is not only a place for announcing street protests or sharing information about these. Social media is also a place for genuinely digital protest in the form of campaigns and conflicts among users. In this chapter, we address the mutual relationship between street protests and their perception by the public. A significant part of this perception emerges in the media in general and in social media in particular (see Elson et al. 2012 and Anstead and O'Loughlin 2014). Not everyone is active in social media, and users do not publish all their ideas. Nevertheless, social media still captures reasonably how people perceive a street protest, due to the large number of users and their somewhat equal share of power.

The role of social media in the emergence of conflicts has been well studied considering street protests and social media as intercorrelated and interdependent (Ayres 1999; Gerbaudo 2012; Valenzuela et al. 2012; Penney and Dadas 2014; Qi et al. 2016). Hussain and Howard (2013) show that mobile phone usage had a crucial role in the success of the Arab Spring social movements, while social media helped to expand it (Lim 2012; Howard et al. 2011). In the Philippines, during the 2001 protest, again, mobile messaging played a prominent role as the place and time of the protest were coordinated through text messages (Shirky 2011). In the case of Occupy Wall Street, Twitter, Facebook, and YouTube played a significant role (DeLuca et al. 2012). These media are successful in mobilizing people since their decentralized structure allows for large-scale cascades of messages (GonzálezBailón et al. 2011). They also have a leading role in the first stages of protests. When traditional media start covering these protests, social media effects mix with those of traditional media (González-Bailón et al. 2013).

The majority of the previous studies focused on how social media has helped to mobilize potential attendees of protests. However, only a few have focused on the 
interplay between street protests and their image in social media and recognized mobile communication as a context for the creation of counter-narratives in street protests. One example is Neumayer and Stald (2014), who studied cases in Denmark and Germany.

We will model the internal dynamics of typical street protests and their relationships with the perception of the broader public who is active on social media. The simultaneous changes in a protest, in terms of the number of attendees and slogans, and the image of the protest in the broader public, in terms of popular topics, are modeled with an agent-based approach. We will use two distinct cases to inform the modeling process one in Iran and another in Germany.

The emergence of social protests has been captured with threshold models of collective behavior by Granovetter (1978) and Kuran (1989). Both models assume that every person has an individual threshold defining the minimal percentage of the protesting population that convinces the individual to join the protest. The rationalchoice interpretation of this threshold is that this is the value where expected benefits exceed the expected costs of protest. In that sense, a low threshold stands for a person with strong concerns who is easily motivated to protest, while a person with a high threshold has few concerns. A reasonably simplifying first assumption, also used by Granovetter, is that thresholds are normally distributed with a certain mean value greater than zero. The persons with thresholds of zero or below are the initial protesters who can trigger others also to start to protest and so on until a final number of protestors is reached. For a normal distribution with a standard deviation below a critical value, only a small fraction ends up in protest, while the protest cascades to almost all people when the standard deviation is slightly above a critical value. Granovetter's model assumes that every person has the information about the global fraction of protesters.

Granovetter's and Kuran's model can explain how it comes that suddenly large protest movements emerge. They however do not take into account that individuals might not assess the fraction of protesting people in the whole population but only those in their immediate social networks. Watts (2002) applied the idea of Granovetter's threshold model to an undirected random network and showed that global cascades can be triggered by one protester while other protesters have equal thresholds (e.g., all 0.2) when the average number of links (i.e., association among protesters) is relatively low (between 1 and 6). The cascades, however, do not happen for denser networks. Dodds and Watts (2004) developed this model into a general model of contagion where individuals may receive several "doses" of motivating messages from others that sum up and trigger protesting when a threshold is exceeded. This model also includes compartmental models from epidemiology, such as the SI (susceptible-infectious) and SIR (susceptibleinfectious-recovered) models, which are the canonical models for the spread of infectious diseases. In our model, we will use the threshold concept as well as the dose concept. We will assume that people can be activated to protest when a fraction of their social contacts is protesting. We will also assume that social media messages function as doses of concern with respect to particular topics for people who are not yet protesting. 
Lohmann (1994) modifies the Granovetter and the Kuran model to focus on participation in a street protest as a costly political action that reveals information on how likely protesters deem political change. Klein and Marx (2018) pursue a similar idea but focus on explicit conversational information exchange between agents and asymmetric learning as a driving factor for the formation of mass movements. In their model, agents have a certain level of grievance and develop expectations of how likely political change is. When two agents meet randomly, one of them can access the other one's attitude. If asked, agents reveal their interest in change. However, since asking has a cost, only those critical of the system try to elicit their conversational partner's attitude. Hence, agents can learn from replies to questions that they ask themselves but also from others asking them or refraining from doing so. This results in asymmetric learning because agents who want change can learn from any interaction while supporters of the status quo only learn from interactions where their conversational partner and not they themselves are given a chance to ask. This means that genuine advocates of change deem change more likely than their peers who are content with the status quo. Moreover, the model shows that agents tend to underestimate the chance for change, while expectations are more accurate for societies with higher spatial or social mobility. Our model implements the idea that expression of one's concern is costly by implementing the possibility of agents sending unpolitical messages instead of expressing their concern. Furthermore, the above-mentioned possibility of social activation honors the fact that people decide whether to join a protest also based on information about the recent number of protesters.

Similarly, Epstein's (2002) model of decentralized rebellion is mainly built on activation but not only triggered by a high number of already activated agents in the neighborhood but also inhibited by repression through the presence of cops. Like the aforementioned models, Epstein's focus is also on fundamental rebellion and hence only captures concern with a single topic (i.e., the current general situation), thereby ignoring the possibility of multiple topics within a protest and agents influencing each other with regard to these topics.

In her investigation of the development of news cycles, Waldherr (2014) touches upon different topics gaining or losing attention within a group of interacting agents. In her model, however, agents are journalists and they are interested in topics rather than concerned about them; thus, attention for a topic has no external consequences like the formation of a protest.

Although our model builds on existing works on protest development as a question of costly choice, social exchange, and information retrieval, it goes beyond previous research by taking into account agents' genuine concern about multiple topics as well as their communicative exchanges on social media. In the following, we analyze two recent cases where protest dynamics and topical changes coevolve and use them to develop our agent-based model. 


\section{Data}

To capture significant similarities and differences in the street protest phenomenon, we deliberately take data from two recent cases of protests from different cultures and political systems: The Iran protests in December 2017 and January 2018 exemplifies a short-term protest that heated up quickly and ended abruptly. In contrast, PEGIDA in Germany since 2014 is a case of long-term motivation of protesters and slow topic shift that can be considered as a social movement. A social movement is a sort of organization with specific goals (Della Porta and Diani 2009, p. 145-150) while a single protest, like the Iran case may not have leaders or definite goals. Protests, in the long run, may turn into a social movement.

\subsection{Iran Protest in 2017/2018}

Our observations on this case stem from primary data analyses of videos and photographs taken at the street protests depicting protest slogans and Iranian online activity, mainly on Telegram, the most popular social media platform in Iran (Techrasa 2016), with regard to the protest.

On December 28, 2017, in Mashhad, capital of Khorasan Razavi province and the second largest city in the country after the capital city Tehran, a demonstration took place in the main square of the city by the invitation of some hardline fundamentalist/conservative political groups opposing the government of president Rohani. The organizers aimed to put pressure on the president by focusing on economic problems and showing how people are supporting the opposition. However, within hours after the protest started, organizers could not control the crowd and slogans radicalized to the critique of the whole political system. Videos from the demonstrations were shared online to millions of people, and consequently, unlike previous Iranian street movements, protests started in more than 100 cities all over Iran (Rahmani Fazli 2018), with the most intense protests occurring in smaller cities. However, only minor physical conflicts with authorities arose, and there was less systematic oppression by the police in comparison with previous protests, because the government tolerated the protests as the president recognized the protesters' right to express their concerns (Euronews 2018). Demonstrations and their repercussion on social media faded out a week after the first protest.

Albeit this short time frame, the protest experienced various shifts of focus visible in daily changes of protest slogans. Overall, we could identify nine different topics shown in Fig. 1. We identified these nine topics by watching all protest videos posted in influencing Telegram channels (73 videos) during the seven days of the protests in more than 36 cities. In total, 78 different slogans were extracted from these videos. Then, we categorized them into nine topics. Figure 1 also shows in how many cities we found slogans from a given topic. Moreover, topics had different 

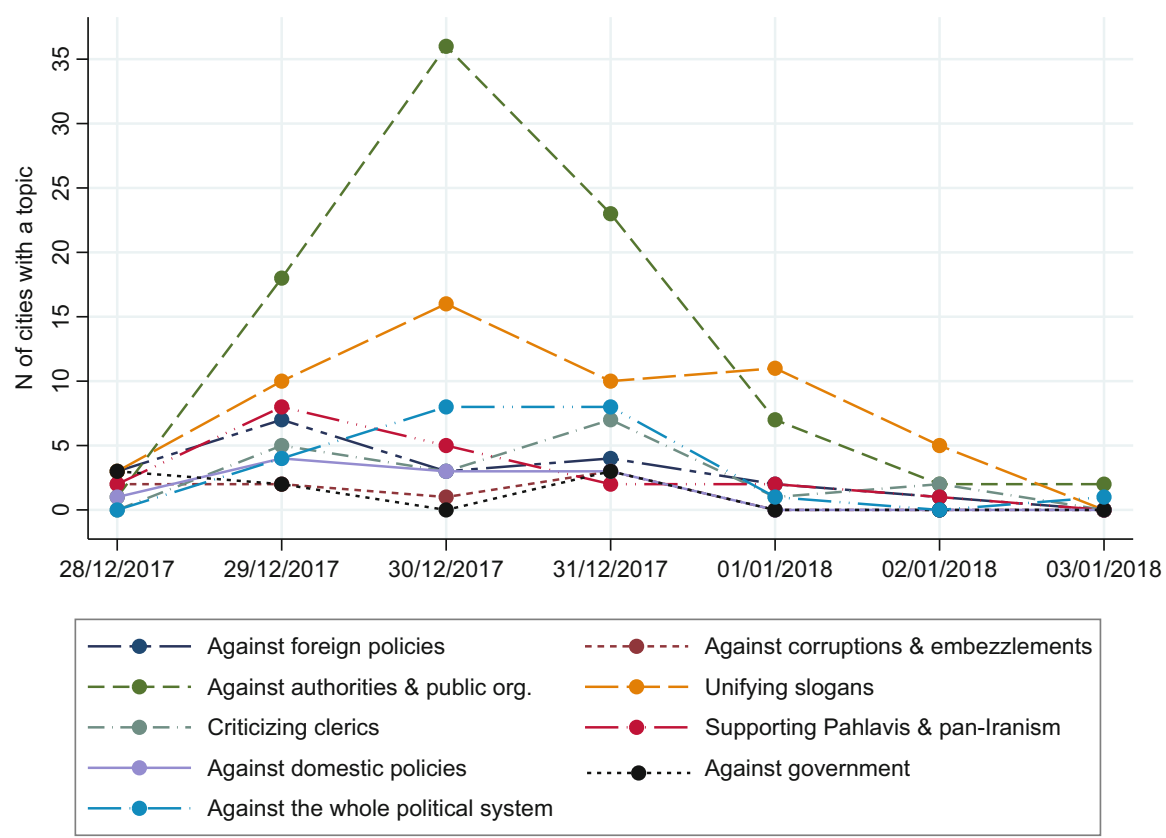

Fig. 1 The number of cities with a topic of protest for the seven days of the protest in Iran

fates along the seven days of protest, as some had uniform popularity and others had more fluctuations in popularity.

Figure 2 shows that different cities had a different number of topics on different days. This underlines the fact that there was not one dominant topic in the protest. This underpins that the movement was decentralized and spontaneous and hence subject to internal dynamics instead of being led by political players pursuing a specific agenda. For example, initial supporters condemned slogans against the whole political regime as some of them are strong defenders of it (Zand 2017). Most political camps in Iran were surprised by the daily developments and hence confined themselves to interpreting events in light of their own goals. This struggle for interpreting the protest was clearly reflected in the first page of political newspapers (Khedmati 2018).

Ordinary non-protesting citizens also interpreted and discussed the developments within families, with colleagues or friends in person and on social media (BBC 2018). Hence, albeit the fact that only about $0.1 \%$ of the population joined street protests directly (Rahmani Fazli 2018), a broad debate in society mirrored the protest topics and tensions between them not only during the protest but still a month after it.

We initially aimed to find the popularity of each protest topic on several social media channels, namely Instagram, Telegram, and Twitter, day by day. This could have shown how the street protest and online trends are interrelated and evolve 


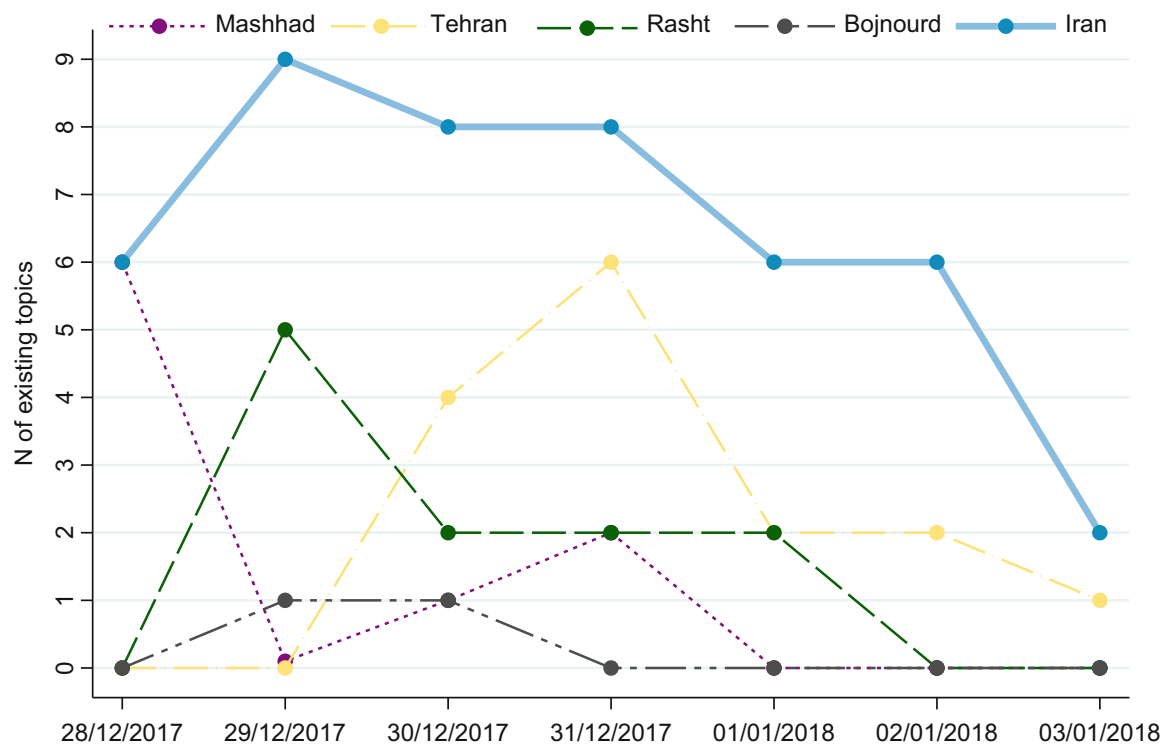

Fig. 2 The number of popular topics in the whole country and four cities during the seven days of protest in Iran

mutually. But tools for analyzing social media turned out to be too expensive and not Persian-friendly enough.

Google Trends, as it is deployed by many scholars (e.g., Choi and Varian 2012; Mellon 2013; Mellon 2014; Minkus et al. 2019) was an alternative for our goal. We searched for the popularity of street slogans on the web, which includes any kind of a text published on the internet (if Google indexes it). This can be a fine proxy of what was important for Iranians during the lifespan of the 2017/2018 protest. Each topic consists of some slogans in the reviewed videos that were gathered from influential Telegram channels. As Google Trends gives indices only for single words or terms, it was impossible to search trends with multiple slogans that constitute one topic. So we searched for single slogans in Iran in Google Trends. Out of 73 slogans, there were data for 10 in Google Trends. The existence of common trends between the number of protesting cities and the Google Trends index shows how hot debates on the internet and in the streets were associated. This is illustrated in Fig. 3.

Figure 3 shows the different patterns of the positive relationship between 10 slogans on the internet and in the streets (in cross-correlation analyses, eight of them had positive relationships). In most cases, the climaxes of online and street topics are the same day or a little retarded or anticipated. It is thus plausible that online and street protests respond to each other. This means that street protests and debates on social media react to each other and can have mutual influence.

The Iran case is an example of protests that start fast and gather people with different topics of interest. In this case, the protest is well-connected to interactions 


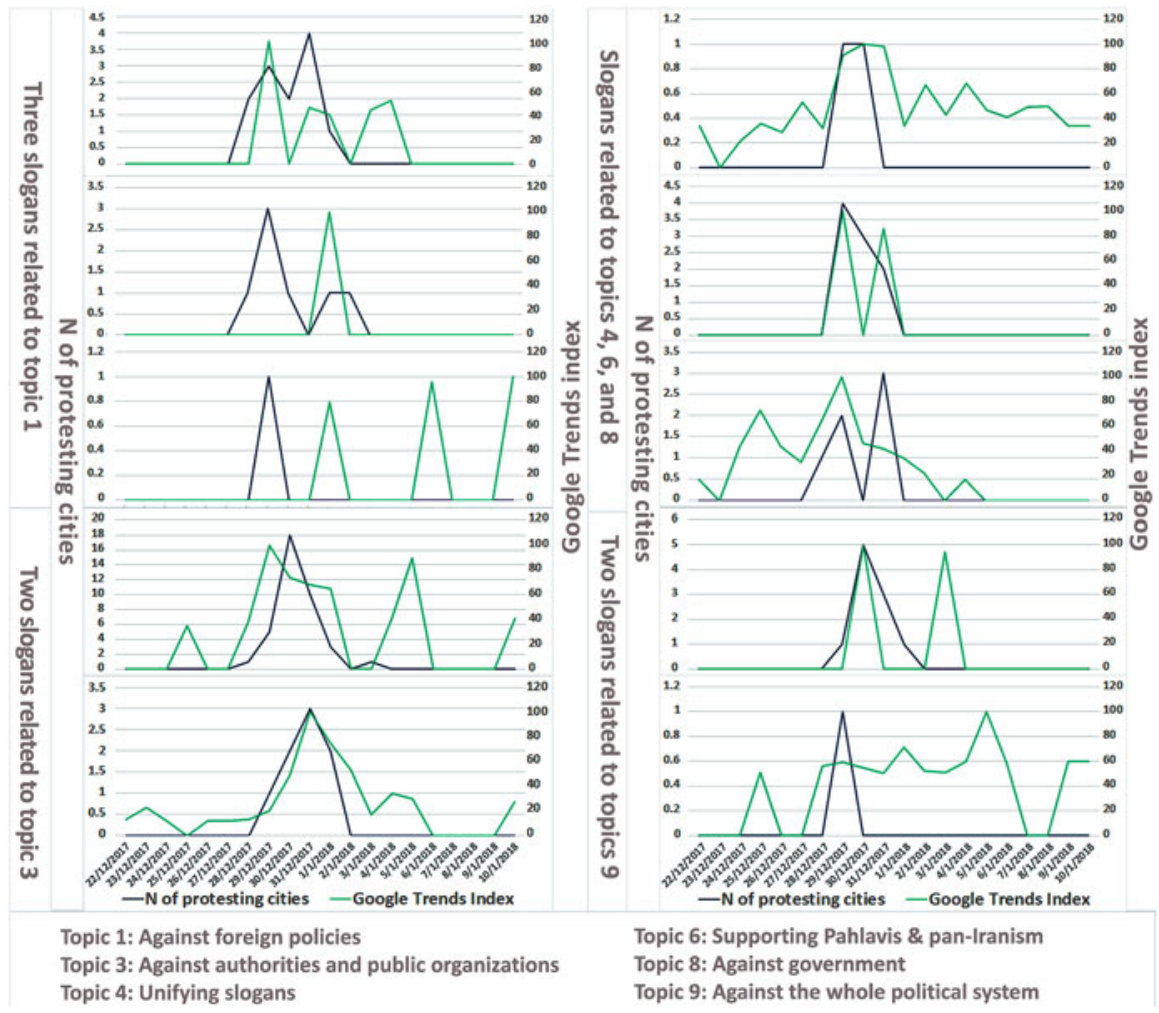

Fig. 3 Examples for the number of protesting cities and Google Trends index during the lifespan of the 2017/2018 Iran protest

among different actors on social media. Change in the popularity of topics in cities and the lateral change in Iranians' online concerns is considerable.

\subsection{PEGIDA, Germany Since 2014 and Ongoing}

The far right-wing populist movement "Patriotische Europäer Gegen die Islamisierung des Abendlandes" (Patriotic Europeans against the Islamisation of the Occident) or short PEGIDA was founded in closed social media groups without party affiliation (Vorländer et al. 2018, p. 2). Soon, a public Facebook page was launched for communication with protesters and general political statements. The page was banned for violation of community standards but immediately reestablished (Vorländer et al. 2018, p. 23-27). Weekly street protests started in the city of Dresden in Saxony, Germany, and sparked protests in other German cities. On October 20, 2014, about 350 protesters joined the first PEGIDA street protest 


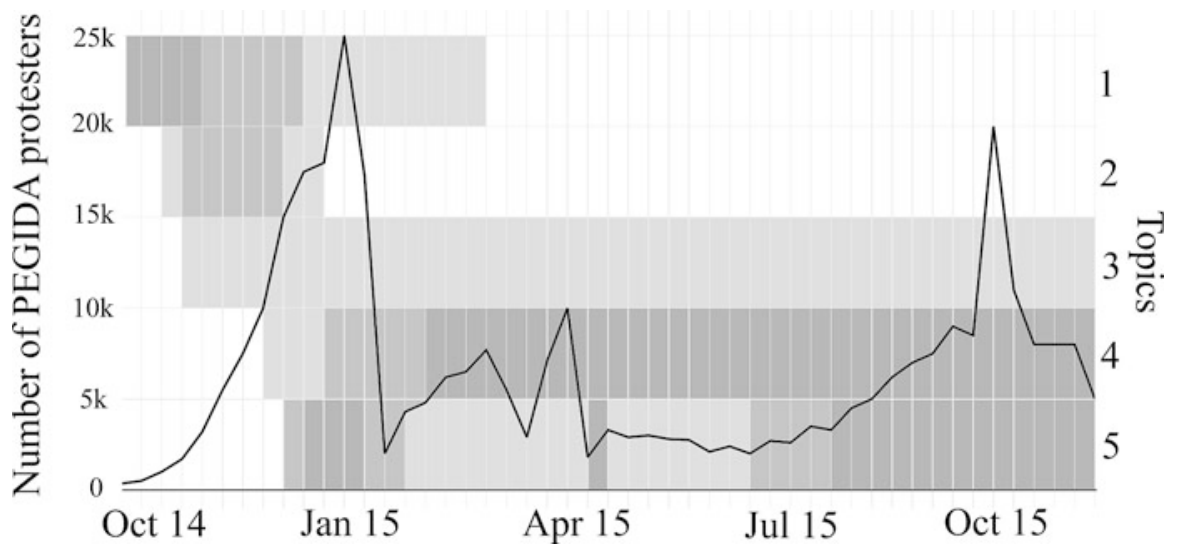

Fig. 4 Number of PEGIDA protesters between October 20, 2014, and November 26, 2015 (Source: Durchgezählt.org) and tendencies in topics lobbied in the protest as found on the PEGIDA Facebook page and elaborated by Rucht et al. (2015) and Vorländer et al. (2016) based on social media communication, slogans at the protest and interviews conducted with protesters. Darker shades mean higher tentative prevalence of the respective topic: 1 = Fear of radical Islam; $2=$ critique of Dresden local refugee policy; $3=$ anti-feminist sentiment; $4=$ fundamental criticism of political establishment and traditional media; $5=$ general xenophobia/anti-refugee sentiment

and expressed their worries about public demonstrations in support of different parties in the Syrian civil war and Islamic extremism. However, this developed into a rejection of Islam and Muslims in general over the next weeks. Moreover, PEGIDA criticized first the local Dresden refugee policy and later the German national one (Vorländer et al. 2016, p. 5-7). Figure 4 shows that the number of supporters constantly rose and peaked at 25,000 on January 12, 2015 (https:// durchgezaehlt.org). After that, the number of protesters decreased to 2000-3000 and PEGIDA organizers amended its topics by a general critique of the political establishment and also the traditional media. When the so-called refugee crisis in the EU arose in summer and autumn 2015, several hundred thousand refugees arrived in Germany and were sent to (often improvised) shelters across the country (Glorius et al. 2018, p. 113). As a consequence, PEGIDA could then mobilize more people again. This resulted in a second peak of 15,000-20,000 protesters on October 19, 2015. After spring 2016 the figures declined again and remain at the level of about 2000 protesters until now (2019). These protesters still oppose migrants, traditional media, and the German political establishment.

During the protest peak time in December 2014 and January 2015, only few protesters interviewed or surveyed by different research teams (Vorländer et al. 2015; Rucht et al. 2015; Geiges et al. 2015) expressed particular issues with Islam, which at the time was the main message conveyed by PEGIDA organizers on banners at the protest or on social media. Instead, protest attendees were more concerned about refugee policy in general and felt alienated from the political 
establishment (which partially led to distrust in the political system altogether) and were unhappy with traditional media news coverage of political events.

Overall, PEGIDA in Germany exemplifies a type of protest that starts without connection to existing political actors and with no revolutionary ideas but focuses on a narrow topic; however, people who are generally dissatisfied join the protest and cause a shift of topics towards a more generalized critique of the political establishment. Furthermore, PEGIDA shows that protests can prevail with a small number of supporters and despite not reaching any of its goals directly impact the general political debate (Vorländer et al. 2018, p. 26). Finally, PEGIDA highlights the importance of understanding the interplay of street protests and their social media image as well as interactions of protest leaders and other political actors.

\subsection{Stylized Data Facts}

Although PEGIDA in Germany and the 2017/2018 protests in Iran seem very different at first glance, our analysis revealed common structural features that a model should capture.

In both cases, topics lobbied in the street shifted away from what organizers of the initial protests intended. This was also noted for the Arab spring by Hussain and Howard (2013) and for Occupy Wall Street in the USA and anti-austerity protests in Greece or Spain by Theocharis et al. (2015). One explanation for these shifts is that protesters have diverse ideas. A few of these ideas can grow more popular and dominate others over time. However, radical shifts do not only occur with regard to topics, but also the number of protesters can drastically increase or decrease either gradually or from one protest day to the next one.

While activity on the street is an important factor for publicity and acknowledgment of a protest, nowadays online space largely contributes to the success of a protest in two ways: Firstly, as spaces for debate, online social networks allow protesters to spread their ideas and develop them further (cf. Lim 2012), as it can, for example, be observed on the PEGIDA Facebook page or in Telegram groups of Iranian protest supporters. Secondly, people can also practically coordinate upcoming street protests by, e.g., sharing information about the time and location, which PEGIDA frequently does prominently by utilizing its page profile and cover pictures for that purpose.

Overall, differences between street protests seem not to be of structural nature, but one should investigate reasons for these differences in specific circumstances of the protest and protesters. However, these specific circumstances can often not easily be empirically accessed, or one may want to predict the fate of future protests based on assumptions about the shape of the specific factors. Hence, our model helps to assess how different circumstances relate to different protest fates. 


\section{Agent-Based Model}

We model the evolution of street protests in terms of individual concerns, social activation, topic selection, and increasing concerns through topic propagation in social media. We only model the activation of protesters and the buildup of concerns and not the dampening and die-out of protests. Before specifying the details, we describe the basic idea.

In our model, several individuals are interconnected in a social network. Each individual holds political concerns of different magnitudes on a finite set of topics. Individuals have different protest thresholds analog to Granovetter (1978). They begin to protest when at least one of their concerns is above the threshold. If this is not the case, they may also join the protest when the fraction of protesting others in their social contacts exceeds the threshold. Thus, individuals can protest because of concerns or because of social activation. The decision to do either is based on the same individual threshold. So, we assume that individuals with a low threshold are more susceptible to both types of activation. They will start to protest already with low concerns or with a low fraction of protesting others. An individual joining a protest decides on one of the topics to protest. A concerned protester selects one of the topics where the concern is above the threshold. Selection is probabilistic with probabilities proportional to concerns. A protester protesting because of social activation has no concern above the threshold and therefore selects a topic from all topics based on probabilities proportional to their concerns. Further on, all individuals, protesting or not, post a message in their social network. Individuals post if they joined a protest and with which topic. Individuals who did not protest post a message unrelated to the protest. The next day people with no concern above threshold read the messages in their social media news feed. Individuals with no concern above their threshold randomly pick one of the messages from their news feed. When this message is protest-related, they increase their concern on the topic of the message. This can be considered a dose of concern analog to Dodds and Watts (2004). People who follow mostly non-protesting others will receive mostly messages that are not protest-related and will thus likely not increase their concerns. This whole process repeats daily and can trigger different fates of protests with respect to the number of protesters and how prevalent the different topics are in the protest. We implemented this model in NetLogo (Wilensky 1999). The model is also provided for reference (Lorenz et al. 2019). It can be downloaded and run in NetLogo, which is free to use.

\subsection{Agents, Follower Network, Thresholds, and Concerns}

The agents in the model are individuals who are connected in a static directed social network built upon initialization. The network can be interpreted as a follower network where an agent can read the social media posts of the other agents following 
but not necessarily vice versa. The follower network is created in two parts. First, a directed preferential attachment network is built, representing links to potential "celebrities" at various magnitudes of fame. This is built by successively creating agents whereupon creation each follows a fixed number of other already existing agents (or all other agents for the very first agents), where agents are selected with probabilities proportional to the number of current followers (plus one to give the newest nodes a non-zero probability to become selected). Second, a friends' network is built. A friend-link is represented by reciprocal follower relations. The friends' network is a random network, where every possible link is created with a probability selected such that the expected number of friends is a certain integer. ${ }^{1}$ That way, we mimic a typical network with mixed properties of social and information networks showing, for example, an in-degree (followers) distribution more skewed and fattailed than the out-degree (following) distribution (Myers et al. 2014).

As variables, each agent has a protest threshold which stays constant after initialization and a vector of concern values on a certain number of topics. The topics are the same for all agents; the concern values can change over time. Protest thresholds are real numbers. Any number larger than one represents an agent who will never join a protest for personal reasons but can impact others' decision to join. Any value of zero or less represents an agent who will always protest regardless of concern or protesting others. Concern values are integers, including zero but less or equal to a certain maximal concern. In a world with five topics, the concern vector $\left[\begin{array}{lllll}0 & 2 & 3 & 0 & 7\end{array}\right]$ represents that the agent is most concerned about topic 5 and not at all concerned about topics 1 and 4. Two other dynamic variables of agents are the protest status, which is either "concern," "social," or "no," and their topic of protest on which they post a message in social media. The protest topic is zero if an agent is not protesting, or the topic (represented by the numerical label of the topic) they chose for the protest. As this is chosen randomly with probabilities proportional to concerns, this is usually a topic on which they have a high concern value. The topic of protest represents a protest-related social media post which can be read by followers. A topic of concern with the value zero represents a posting not related to protest.

\subsection{Agents' Activities}

In the full model, there are three protest mechanisms: the decision to protest because of concerns above threshold (concern protest), the increase of concern through information from social media (social media concern), and the decision to protest because of many others in the social network protest (social activation).

\footnotetext{
${ }^{1}$ Besides a random graph the NetLogo model also includes options to build the friends' network based on a ring or on several cliques for robustness tests. These are not used in this work.
} 
These mechanisms can be independently switched on and off. In the following, we consider that all are switched on.

On each tick (we can think of a day) agents do the following activities.

Step 1. All agents which are not already concerned enough to protest read their news feed and compute the fraction of the people they follow who protested. The news feed represents the list of social media messages from the last day an agent reads. In the model, it is a list of the topics of protest and non-protest-related messages of all agents the agent follows. From the news feed, the agent also extracts the fraction of protesting people.

Step 2. All agents decide if they join the protest.

Step 2.1. (Concern protest) An agent checks if a concern on at least one topic is greater than the individual protest threshold times the maximally possible concern value (a global parameter set to ten in the following). If this is the case, the agent sets the protest status to "concern." We refer to this condition as "concern above the threshold." An agent with protest status "concern" then selects the topic of concern from all the topics that are above the threshold randomly with probabilities proportional to concern values.

Step 2.2. (Social media concern) Agents without concerns above the threshold will read their news feeds and select one topic of concern from this list at random. This can well be zero, representing a message which is not protest-related. In this case, nothing more happens. If it is a protest topic, the agent will increase the concern value on that topic by one. Note that, agents with a concern above the threshold will not increase any concerns anymore, because we assume that an agent only needs one concern above the threshold to join, and we are only modeling the buildup of one particular protest.

Step 2.3. (Social activation) Agents without concerns above the threshold check if the fraction of people followed who protest is greater than the threshold. If this is the case, the agent is socially activated and sets the protest status to "social" otherwise to "no." If the agent protests, one of the topics is selected for the protest at random with probabilities proportional to the concern values. This selection happens even though the concerns themselves are all not above the threshold. The rationale is that for joining a protest, even when only socially activated, one needs a topic of concern.

\subsection{Initial Conditions and Stopping Rules}

The initialization of a simulation run (setup procedure) is done as follows. First, a fixed number of agents is created. Then, directed links are created using the preferential attachment generator and, as described above, further reciprocal friends'

\footnotetext{
${ }^{2}$ The protest threshold is multiplied with the maximal concern to match the concern values (from, e.g., $\{0,1, \ldots, 10\})$ with protest thresholds (from $[0,1]$ ).
} 
links are created in a random network. Network generation is steered by the parameters following and friends, which describe the desired average number of directed and reciprocal links an agent should have. Agents' static protest thresholds are random numbers from a normal distribution with mean threshold level and standard deviation threshold-dispersion. Agents' dynamic concern vectors are topicnum integers between zero and max-concern. The concern value on each topic is initialized as a binomial random number with probability initial-concern-level. This implies that the expected concern on each topic for each agent is initialconcern-level times max-concern. The three mechanisms of concern protest (CP), social-media-concern (SMC), and social activation (SA) described above can all be independently switched "on" and "off." All "on" specifies the full model.

It turns out that only the five combinations of CP, SA, CP-SA, CP-SMC, and CP-SMC-SA are sensible configurations to distinguish. Just SMC will never spark anyone to protest, and SMC-SA would fully coincide with SA with respect to the protest status of agents. A logical analysis of all model variants shows that an agent can only experience three types of transitions of the protest status: "no" $\rightarrow$ "concern", "no" $\rightarrow$ "social", and "social" $\rightarrow$ "concern". Therefore, the total number of protesters (genuinely concerned or socially activated) can only increase or stay constant. As already mentioned, the decline of protests was deliberately not the aim of the modeling.

Only when social media concern is switched on, the concerns of agents can increase. Thus, it is easy to see that in the $\mathrm{CP}$ regime the total number of protesters is reached after one time-step, and in the SA and CP-SA regime, the total number of protesters is reached when the number of protesters stays constant for one timestep. The chosen protest topics may change but the distribution for the probabilistic selection stays constant.

When social media concern is switched on, every agent who is at some point following a protesting agent will successively increase the concern on at least one topic in the long run. Consequently, the agent will turn into a concerned protester unless the agent has a protest threshold above one, which rules out any protest. Thus, in most configurations with social media concern, all agents with thresholds below one end up with protest status "concern." Furthermore, the concerns of agents remain stable once they are concerned protesters. Therefore, also the distribution for the random selection of topics of concern in the whole society stabilizes once all protesters turn to be concerned protesters. We use these insights to define the stopping rules for simulation runs.

\section{Simulation Experiment}

In our model exploration, we used always the same network generation parameters. We assume that each agent follows five others (directed links in a preferential attachment network) and has five friends (undirected links in a random network). Furthermore, the maximum possible concern is fixed at ten. First, we work with 
distinct values of the threshold level, initial concern, and threshold-dispersion to represent the cases of Iran and Germany. Afterward, we explore the whole space of the three parameters to gain general insights on the model mechanics that help understand other protests as well as possible future developments in our two example cases. When interpreting the simulation outcome, one should bear in mind that the total population in the model does not necessarily represent everyone in society but is conceptually limited to those active people linked to the protest on social media as well as generally sympathetic about the protest and any of its topics. Moreover, the time-frame is different for different protests based on how dynamical they are.

\subsection{The Iran Case in the Model}

The empirical observation of the Iran case (see Sect. 2.1) can be translated to nine topics and a low initial-concern-level (0.1), which should mirror the fact that protests broke out suddenly and was not connected to one rising specific concern. The medium threshold level of 0.5 represents the fact that people generally had a sense of urgency and willingness to express their views but at the same time, they would not campaign on the streets lightheartedly. Since the Iran protest evolved dynamically, one should understand a time-step in the model as a few hours in reality, while the population consists of all citizens who consider street protests an appropriate and efficient way of expressing their political opinion, regardless of their political stripe.

Figure 5 depicts a simulation run, exploiting such parameter values. It compares snapshots of the model world to the overall development of the number of protesters and prevalence of topics in the protest. In the model world, non-protesting agents are black, while protesting agents have the color of their protest topic shaded by their concern value on that topic. Agents with protest status "concern" are filled dots, while the protest status "social" is indicated as white-filled circles. Agents are arranged according to the structure in their preference attachment (follower) network, and an agent's size indicates its centrality in that network.

Figure 5 shows that initially, only a few people protest, but numbers steadily increase quickly. The social dimension of the protest is most important after it has gained considerable concern-driven support (starting at step 27); at this point, some people would not yet have joined the protest out of concern but they do join because of social activation. This is crucial here because running the setting without social activation witnesses the protest dying out. However, social activation does not mean that people are not concerned at all and only join because they want to meet their friends on the street. Instead, the presence of people they know may raise one's faith in the protest's success or even a sense of safety when protesting, as Klein and Marx (2018) suggest. Once the protest has consolidated in numbers of protesters, the socially motivated ones also become genuinely concerned (starting from step 36). There are constant minor fluctuations between topics showing that many people are concerned about more than one topic and that slogans in the protest often depend on 

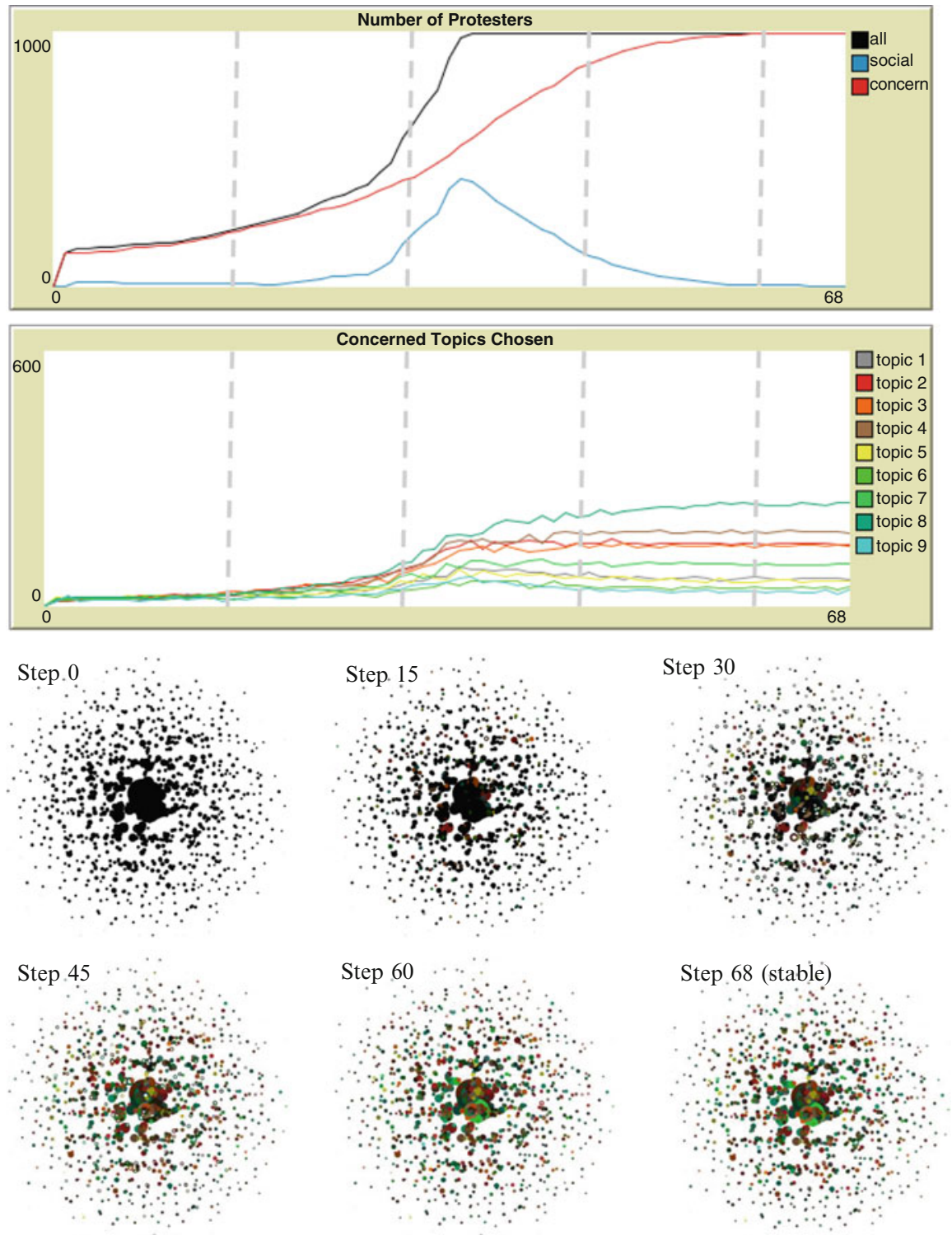

Fig. 5 Simulation run of the Iran case (parameter setting cf. Table 1)

up-to-the-minute news. This amounts to a different focus of protesters in different clusters within the network (comparable to different cities in Iran-not visible in the figure) and at different times. 


\subsection{The Germany Case in the Model}

Representing PEGIDA in the model works with five topics and the same initialconcern-level $(0.1)$ as in the Iran case above but with a higher threshold level of 0.7. This higher threshold represents the fact that issues of the PEGIDA movement are more confined to a single topic area and also less severe for people's everyday lives: In order to lobby a topic in the street protest, an actor has to perceive issues with respect to that topic as particularly severe. One time-step in the model can be identified with one day of the PEGIDA protest, which evolved more slowly than the Iran case. The population also does not represent the whole political landscape in Germany but includes only those possible protesters who sympathize with rightwing ideas or are deeply disappointed with the political and social establishment.

In Fig. 6, one can see one possible situation of how a protest given these input parameters can unfold. The movement takes about 50 steps of only a few people protesting, which corresponds to smaller actions taken by PEGIDA organizers and core supporters prior to focusing on PEGIDA itself. However, after that initial phase, people join quickly and they mostly do that because of genuine concern, which they build up in the meantime, not because of social activation. That again is in line with the empirical findings showing that despite organizers' appeal to moderate views, protesters expressed genuine right-wing sentiment (Vorländer et al. 2018, p. 64-66). Initially, a variety of topics is present within the protest and one of them temporarily becomes the most important one (in reality it was "anti-refugee"). However, later (at step 70) a second topic (in reality it was "critique of the political establishment") emerges and most protesters now (at step 99) regard this as their primary concern. That protesters become part of the same filter bubble (online and offline) also contributes to the focus on a single protest topic. Nevertheless, the first topic still maintains considerable support and is simply outnumbered by new protesters supporting the new one. While social activation has a smaller influence than in the Iran case simulation on the number of protesters, it is the main facilitator for the second topic overtaking the first topic. Additional simulations with the same realization of random events but without social activation show that the overtaking phenomenon does not occur in the case when social activation is turned off. In reality, PEGIDA organizers frequently encouraged protesters to actively reach out to their friends (Rucht et al. 2015, p. 17-18) and while these friends may not have shared a strong anti-refugee sentiment, they held a generally critical opinion of the government and joined for this reason (Rucht et al. 2015, p. 48-51).

\subsection{Comparison Between the Iran and Germany Model Simulations}

The parameter values for the simulations for the two cases are summarized in Table 1. The similarity of parameter values for the Iran and Germany cases 

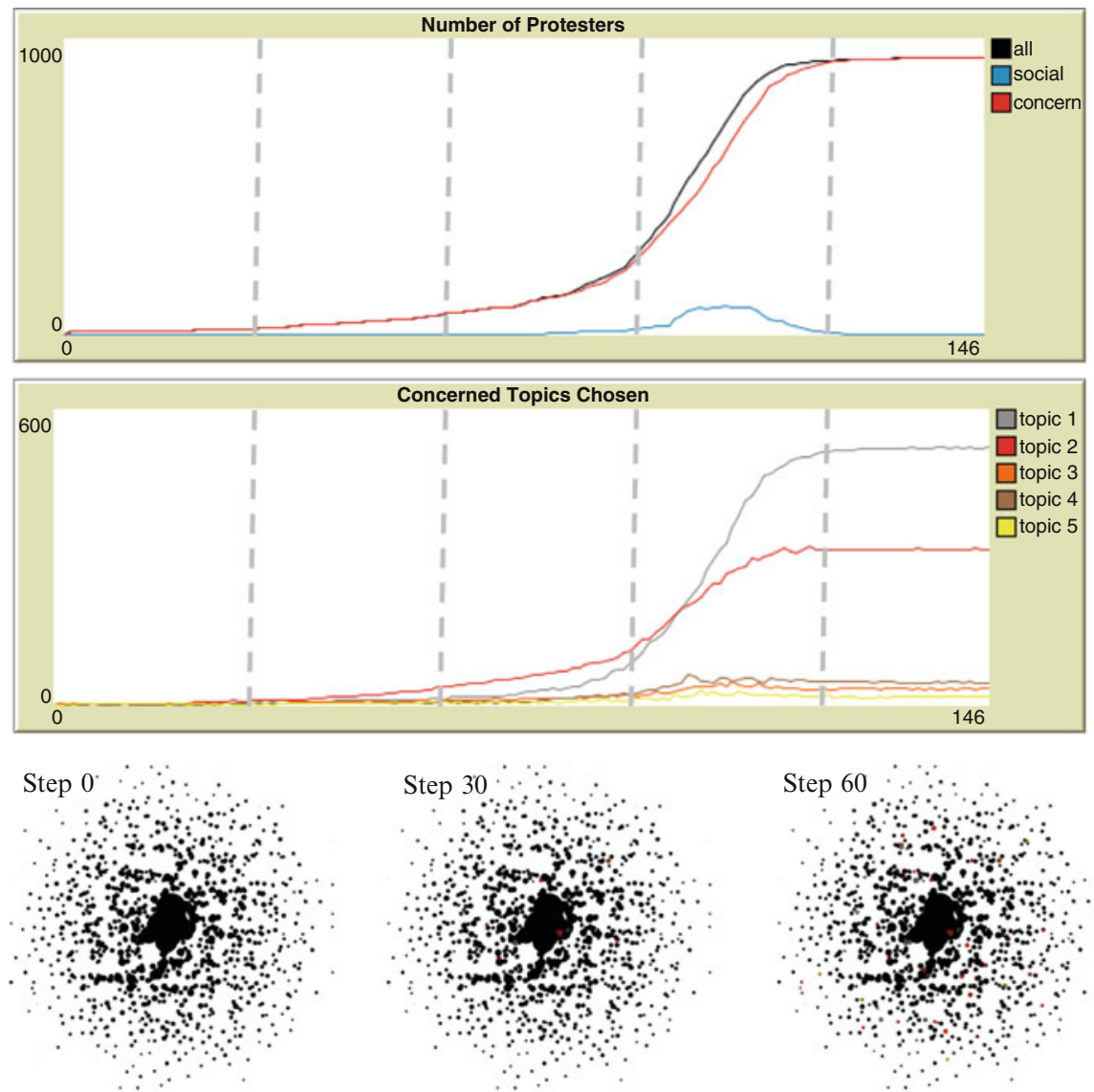

Step 90

Step 120

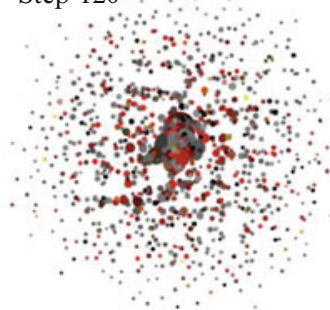

Step 146 (stable)

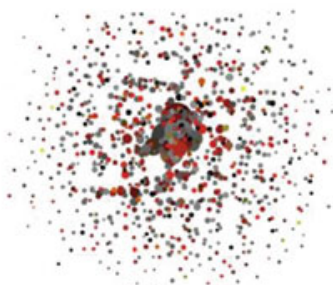

Fig. 6 Simulation run of the Germany case (parameter setting cf. Table 1)

indicates that they are structurally related. The cases differ in the perceived overall importance of the protest cause which translates to a lower threshold level in the model of the Iran case. They also differ in the number of potential protest topics (fewer in Germany). Furthermore, while the specific features of the empirical cases (multiplicity of topics for Iran; single important topic and the crucial role of social 
activation for Germany) are common for the corresponding parameter values, the effects are not guaranteed to occur under a given setting. That is the case because case-specific features like the layout in the random friendship network or the individual properties of central hubs in the preferential attachment network play an important role in the simulation outcome, too. Such aspects are specific features of a society (Vaisey and Lizardo 2010); the present model suggests that these casedependent societal aspects can explain why seemingly similar protests experience different fates in empirical cases.

\subsection{Parameter Study}

In the following, we analyze how the final number of protesters and the distribution of protest topics depend on the three protest mechanisms as well as the threshold level and the initial-concern-level in the society. To that end, we made several simulation runs using NetLogo's BehaviorSpace (cf. Lorenz et al. 2019), setting all other parameters to the Iran case from Table 1. For an initial-concern-level of 0.1 , we vary the threshold level from 0 to 0.8 in steps of 0.05 . Furthermore, we also vary the initial-concern-level in steps of 0.05 from 0 to 0.5 , for a threshold level of 0.5 . We either run the simulation until a natural stopping criterion is reached (cf. Sect. 3.3) or stop it after 1000 time-steps. This ensured that we have reached a final configuration where the number of protesters and the concerns do not change anymore. What remains are stochastic changes in the protest topics selected, because agents may have several topics above the threshold. We computed fifty simulation runs for each configuration using no prespecified random seeds. Based on how often each topic is selected for protest, one can compute an effective number of topics $1 / \sum p_{i}{ }^{2}$ where the summation is over all topics and $p_{i}$ is the number of agents protesting for topic $i$ divided by the total number of protesting agents. This number is analog to the effective number of parties of Laakso and Taagepera (1979).

Table 1 Parameter values for the simulation runs with respect to the two cases

\begin{tabular}{l|c|c}
\hline Parameter & Iran case & Germany case \\
\hline Population & 1000 & 1000 \\
\hline Following & 5 & 5 \\
\hline Friends & 5 & 5 \\
\hline Num-topics & 9 & 5 \\
\hline Max-concern & 10 & 10 \\
\hline Initial-concern-level & 0.1 & 0.1 \\
\hline Threshold level & 0.5 & 0.7 \\
\hline Threshold-dispersion & 0.2 & 0.2 \\
\hline RandomSeed & 16 & 17
\end{tabular}

The randomSeed specifies the sequence of random events used in the NetLogo model (Lorenz et al. 2019) 


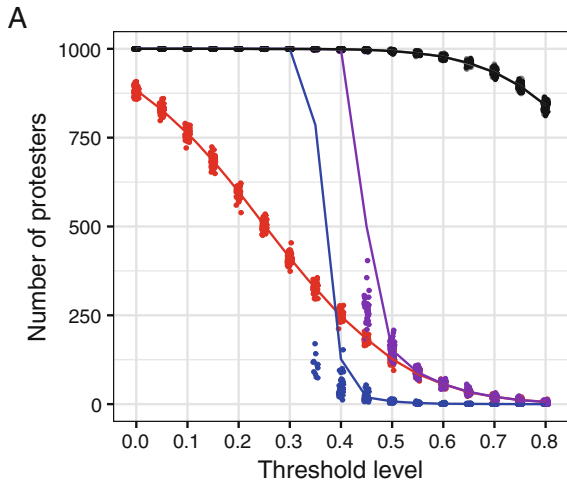

- concern protest (CP)

- social activation (SA)

- $\mathrm{CP}$ and SA

- $\mathrm{CP}$ and social media concern (SMC)

- Full model CP, SMC, and SA

B

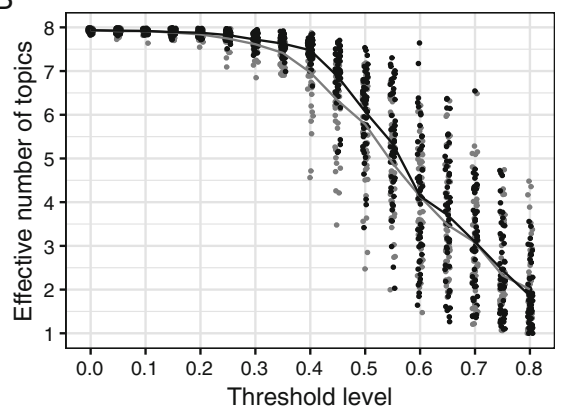

Initial concern level 0.1 Threshold dispersion 0.2
C

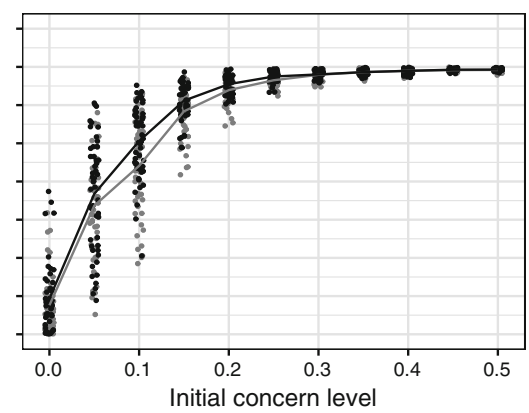

Threshold level 0.5 Threshold dispersion 0.2

Fig. 7 Results for the parameter study. The threshold level is the mean of the individual thresholds. Note, that the gray dots for "CP and social media concern (SMC)" configuration in Panel A are mostly covered by black dots

Figure 7 shows the results. Dots show data points for individual simulation runs. Lines show the mean value over all simulation runs for this parameter setting.

Panel A shows the number of final protesters with respect to the threshold level. With only concern protest, the number of protesters smoothly declines with a rising threshold level. This is simply explained by initial conditions. With social activation, we have a threshold regime: At a critical threshold level of about 0.35 , regimes change from a full protest to almost no protesters. This is similar to Granovetter (1978) and Watts (2002). We have a mixed model with a network as Watts and heterogeneous thresholds as Granovetter. This critical threshold is shifted slightly upwards when concern protest and social activation are combined. When social media concern is added, protest builds up, sometimes quite slowly, until usually all individuals with thresholds below one protest. This is independent of the mechanism of social activation being on or off. For relatively high threshold levels, there is a sizable amount of such individuals who never protest.

Panel B shows the effective number of topics for the same setup. This is only of interest when social media concern is involved. In other cases, without social media, 
no particular structure of topics evolves. This implies an effective number of topics around eight. An effective number of nine would only occur with perfect equality of all topics. Random fluctuation brings the number to about eight. The same happens with social media when the threshold level is relatively low but changes with higher threshold levels. With threshold levels around 0.5, a hierarchy of topics evolves with an effective number of topics around 5. With even higher threshold levels, this reduces too much lower numbers of effective topics around 2 . This essentially means that one topic dominates while others only play a minor or no role.

Panel $\mathrm{C}$ finally shows how the effective number of topics changes with increasing initial concerns for a fixed threshold level of 0.5. Panels B and C together show that a larger distance between threshold level and initial concern implies a lower number of effective topics. Only in these cases, social media has time to build a hierarchy of topics before an overall protest emerges. The combination of concern protest and social media with social activation implies a slightly higher number of effective topics. This happens due to the fact that socially activated actors bring new topics to the protest.

\section{Discussion}

The basic model version introduced in this paper can reproduce different empirically observed fates of protests and describe mechanisms that possibly cause these fates. We were able to show which individual protesters' properties were necessary to get the patterns empirically observed in the Iran and Germany case studies. Combining empirical studies of processes and understanding their possible causes in the model thereby is a key to understand how the relation of individual decisions and exchange online leads to street protests. The die-out of protest, however, was not part of this study.

The parameters explicitly modified in our model only provide necessary conditions for a certain protest fate. Specific features of the society in which the protest takes place are important for its fate too. In the model, these features are the network layouts and especially the positions of agents with certain concern levels on certain topics within the networks. Moreover, this model version is deliberately kept simple and hence cannot capture other aspects of social media interactions and street protests in reality. In an extended model, the protest could be given a more active role in the sense of introducing interaction among protesters in the streets leading to additional concern change or additional messages sent from the protest or individual protesters to the social network. The decision of whether or not to join a protest may need revision to capture real actors' decisions more closely. Finally, one may consider including external influences that, at a pre-defined simulation step or when certain conditions are met, lead to an exceptional emotional dampening for some or all agents regarding a specific topic or across all topics. For example, government reactions, such as suppression or policy change, are not included yet. 
Acknowledgments The work was initiated on the BIGSSS Summer School in Computational Social Science 2018 at Jacobs University Bremen funded by Volkswagen Foundation (Grant Number 92145). We thank all experts and participants for their feedback. The work is also part of Jan Lorenz' project on Opinion Dynamics and Collective Decision funded by the German Research Foundation (DFG grant number 265108307) which covered the travel cost for Asgharpourmasouleh and Fattahzadeh.

\section{References}

Anstead, N., \& O'Loughlin, B. (2014). Social media analysis and public opinion: The 2010 UK general election. Journal of Computer-Mediated Communication, 20(2), 204-220.

Ayres, J. M. (1999). From the streets to the Internet: The cyber-diffusion of contention. The Annals of the American Academy of Political and Social Science, 566(1), 132-143.

Choi, H., \& Varian, H. (2012). Predicting the present with Google Trends. Economic Record, 88, $2-9$.

Count Love. (2019). Search. Retrieved June 16, 2019, from https://countlove.org/statistics.html

Della Porta, D., \& Diani, M. (2009). Social movements: An introduction. New York: John Wiley \& Sons.

DeLuca, K. M., Lawson, S., \& Sun, Y. (2012). Occupy Wall Street on the public screens of social media: The many framings of the birth of a protest movement. Communication, Culture \& Critique, 5(4), 483-509.

Dodds, P., \& Watts, D. (2004). Universal behavior in a generalized model of contagion. Physical Review Letters, 92, 218701.

Elson, S. B., Yeung, D., Roshan, P., Bohandy, S. R., \& Nader, A. (2012). Using social media to gauge Iranian public opinion and mood after the 2009 election. Santa Monica, CA: Rand Corporation.

Epstein, J. M. (2002). Modeling civil violence: An agent-based computational approach. Proceedings of the National Academy of Sciences of the United States of America, 99, 7243-7250. https://doi.org/10.1073/pnas.092080199.

Euronews. (2018, January 17). Protests in Iran finished in favor of Rohani. Retrieved from https:// fa.euronews.com/2018/01/17/

Geiges, L., Marg, S., \& Walter, F. (2015). Pegida: die schmutzige Seite der Zivilgesellschaft? Bielefeld: transcript Verlag.

Gerbaudo, P. (2012). Tweets and the streets: Social media and contemporary activism. London: Pluto Press.

Glorius, B., Schondelmayer, A. C., \& Dörfel, R. (2018). ,Wandel durch Annäherung“"? Gesellschaftliche Konflikte im Kontext der Flüchtlingsunterbringung im ländlichen Sachsen. In: S. Goebel, T. Fischer, F. Kießling, \& A. Treiber (Eds.), FluchtMigration und gesellschaftliche Transformationsprozesse. Wiesbaden: Springer VS.

González-Bailón, S., Borge-Holthoefer, J., \& Moreno, Y. (2013). Broadcasters and hidden influentials in online protest diffusion. American Behavioral Scientist, 57(7), 943-965. https://doi.org/10.1177/0002764213479371.

González-Bailón, S., Borge-Holthoefer, J., Rivero, A., \& Moreno, Y. (2011). The dynamics of protest recruitment through an online network. Scientific Reports, 1, 197.

Granovetter, M. (1978). Threshold models of collective behavior. American Journal of Sociology, 83, 1420.

Howard, P. N., Duffy, A., Freelon, D., Hussain, M. M., Mari, W., \& Maziad, M. (2011). Opening closed regimes: what was the role of social media during the Arab Spring? SSRN Electronic Journal. https://doi.org/10.2139/ssrn.2595096.

Hussain, M. M., \& Howard, P. N. (2013). What best explains successful protest cascades? ICTs and the fuzzy causes of the Arab Spring. International Studies Review, 15(1), 48-66. 
Iran protests: Social media messaging battle rages. (2018, January 7). Middle East. Retrieved from https://www.bbc.com/news/world-middle-east-42566083

Khedmati, M. (2018, December 30). What did Newspapers do in "Day protests"? Iranian Students News Agency. Retrieved from https://www.isna.ir/news

Klein, D., \& Marx, J. (2018). Wenn Du gehst, geh ich auch! Die Rolle von Informationskaskaden bei der Entstehung von Massenbewegungen. PVS Politische Vierteljahresschrift, 58(4), 560 592.

Kuran, T. (1989). Sparks and prairie fires: A theory of unanticipated political revolution. Public Choice, 61(1), 41-74.

Laakso, M., \& Taagepera, R. (1979). "Effective" number of parties. Comparative Political Studies, 12(1), 3-27.

Lankina, T. V. (2014). Daring to protest: When, why, and how Russia's citizens engage in street protest. PONARS Eurasia Policy Memo, no. 333. Washington, DC: George Washington University.

Lim, M. (2012). Clicks, cabs, and coffee houses: Social media and oppositional movements in Egypt, 2004-2011. Journal of Communication, 62(2), 231-248.

Lohmann, S. (1994). The dynamics of informational cascades: The Monday demonstrations in Leipzig, East Germany, 1989-91. World Politics, 47(1), 42-101.

Lorenz, J., Asgharpourmasouleh, A., Fattahzadeh, M., \& Mayerhoffer, D. (2019). janlorenz/ProtestFate: Published Version (Version v1.0). Zenodo. https://doi.org/10.5281/zenodo.3243818.

Mellon, J. (2013). Where and when can we use Google Trends to measure issue salience? PS: Political Science \& Politics, 46(2), 280-290.

Mellon, J. (2014). Internet search data and issue salience: The properties of Google Trends as a measure of issue salience. Journal of Elections, Public Opinion \& Parties, 24(1), 45-72.

Minkus, L., Deutschmann, E., \& Delhey, J. (2019). A Trump effect on the EU's popularity? The US Presidential Election as a Natural Experiment. Perspectives on Politics, 17, 399-416.

Myers, S. A., Sharma, A., Gupta, P., \& Lin, J. (2014). Information network or social network? In Proceedings of the 23rd International Conference on World Wide Web - WWW '14 Companion. New York: ACM Press.

Neumayer, C., \& Stald, G. (2014). The mobile phone in street protest: Texting, tweeting, tracking, and tracing. Mobile Media \& Communication, 2(2), 117-133.

Penney, J., \& Dadas, C. (2014). (Re) Tweeting in the service of protest: Digital composition and circulation in the Occupy Wall Street movement. New Media \& Society, 16(1), 74-90.

Qi, H., Manrique, P., Johnson, D., Restrepo, E., \& Johnson, N. F. (2016). Open source data reveals connection between online and on-street protest activity. EPJ Data Science, 5(1), 18.

Rahmani Fazli, A. (2018, March 11). Untolds of Minister of State on the Day Protest. Interview with Alef website. Retrieved December 16, 2018, from https://www.alef.ir/news/ 3961220074.html

Rucht, D., Daphi, P., Kocyba, P., Neuber, M., Roose, J., Scholl, F., et al. (2015). Protestforschung am Limit. Eine soziologische Annäherung an Pegida. Berlin: ipb working papers.

Shirky, C. (2011). The political power of social media: Technology, the public sphere, and political change. Foreign Affairs, 90, 28-41.

Techrasa. (2016, August 26). Infographic: Social Media Demographics in Iran. Retrieved from http://techrasa.com/2016/08/26/infographic-social-media-iran/

Theocharis, Y., Lowe, W., Van Deth, J. W., \& García-Albacete, G. (2015). Using Twitter to mobilize protest action: online mobilization patterns and action repertoires in the Occupy Wall Street, Indignados, and Aganaktismenoi movements. Information, Communication \& Society, 18(2), 202-220.

Vaisey, S., \& Lizardo, O. (2010). Can cultural worldviews influence network composition? Social Forces, 88(4), 1595-1618.

Valenzuela, S., Arriagada, A., \& Scherman, A. (2012). The social media basis of youth protest behavior: The case of Chile. Journal of Communication, 62(2), 299-314. 
Vorländer, H., Herold, M., \& Schäller, S. (2015). Wer geht zu PEGIDA und warum? Eine empirische Untersuchung von PEGIDA-Demonstranten in Dresden. Schriften zur Verfassungsund Demokratieforschung. Dresden: Zentrum für Verfassungs-und Demokratieforschung.

Vorländer, H., Herold, M., \& Schäller, S. (2016). PEGIDA: Entwicklung, Zusammensetzung und Deutung einer Empörungsbewegung. Wiesbaden: Springer-Verlag.

Vorländer, H., Herold, M., \& Schäller, S. (2018). PEGIDA and new right-wing populism in Germany. Basingstoke: Palgrave Macmillan.

Waldherr, A. (2014). Emergence of news waves: A social simulation approach. Journal of Communication, 64(5), 852-873.

Watts, D. (2002). A simple model of global cascades on random networks. Proceedings of the National Academy of Sciences of the United States of America, 99, 5766.

Wilensky, U. (1999). NetLogo. Retrieved from http://ccl.northwestern.edu/netlogo/. Evanston, IL: Center for Connected Learning and Computer-Based Modeling, Northwestern University.

Zand, S. (2017, December 30). How the protests of "no to inflation" started? Fararu News Agency. Retrieved from https://fararu.com/fa/news

Open Access This chapter is licensed under the terms of the Creative Commons Attribution 4.0 International License (http://creativecommons.org/licenses/by/4.0/), which permits use, sharing, adaptation, distribution and reproduction in any medium or format, as long as you give appropriate credit to the original author(s) and the source, provide a link to the Creative Commons licence and indicate if changes were made. The images or other third party material in this chapter are included in the chapter's Creative Commons licence, unless indicated otherwise in a credit line to the material. If material is not included in the chapter's Creative Commons licence and your intended use is not permitted by statutory regulation or exceeds the permitted use, you will need to obtain permission directly from the copyright holder. 